\title{
RHETORICAL DESIGN GAME FOR EXPECTATION ALIGNMENT
}

\author{
Koskela, Mikael; Pikas, Ergo \\ Danish Technical University (DTU)
}

\begin{abstract}
While the form of building construction delivery known as Integrated Design-Build (or Integrated Project Delivery) is necessary for handling the complexity of modern projects, it raises up a host of problems due to the amount and variety of stakeholders that are brought together to co-design. Namely, the difficulty in forming a shared mental model of expectations regarding the project can cause disappointment in the results, as well as time and cost overruns. This paper is about creating an intervention to alleviate those issues. Employing knowledge from the field of rhetoric in design, and of mental models, two Integrated Design-Build workshops were analyzed to extract a set of rhetorical topics (topoi) to all such sessions. A design game was formulated around the empirical data by an iterative design process, following established design game theory. The game was found to indeed more than double the alignment of a group's individual mental models, though more testing is needed to validate this.
\end{abstract}

Keywords: Rhetoric, Mental models, Collaborative design, Teamwork, Early design phases

\section{Contact:}

Koskela, Jaakko Otso Mikael

Danish Technical University (DTU)

Management Engineering

Denmark

mkl.koskela@gmail.com

Cite this article: Koskela, M., Pikas, E. (2019) 'Rhetorical Design Game for Expectation Alignment', in Proceedings of the 22nd International Conference on Engineering Design (ICED19), Delft, The Netherlands, 5-8 August 2019. DOI: $10.1017 /$ dsi.2019.165 


\section{INTRODUCTION}

Nowadays the result of architects' and design managers' toil is not simply buildings, but complex sociotechnical systems. And given the increasing strictness of regulations and the raising of owner demands, it is no wonder that in the past few decades the early stages of sociotechnical system design have come to accommodate a substantial array of actors to complement the architects' capabilities (Urup 2016).

This modern form of project delivery goes by the name Integrated Design-Build (Urup 2016) or Integrated Project Delivery (Eckblad, Ashcraft et al., 2007). While this shift has been critical to achieving the ability to fulfil present-day building requirements, it has brought about a surge in complexity due not only to increasing the amount of diverse knowledge to be fused together, but also to the large and dynamic amount of stakeholders, which summons forth both the benefits and the negative side of heterogeneous collaboration. Considering that there is bound to be some level of friction even in collaboration amongst professionals of similar backgrounds, it is obvious that teams endowed with diverse (and occasionally divergent) norms, interests and values are fertile ground for inefficiency and discord, sometimes even strife. The dark side of human nature tend to foment up in egocentric groups when a common ground is not readily available: insufficient knowledge sharing (Thuesen 2007), lack of coordination (Apelgren, Richter et al., 2005), even collective shirking from responsibilities (Henisz, Levitt et al., 2012). And the results are deplorable: significant time overruns, excessive construction costs, and low quality of the final sociotechnical system (Apelgren, Richter et al., 2005, Siebken Schultz 2012).

The vexing characteristics associated with 'wickedness' of the design task hamper the formation of shared understanding within design teams; it is often difficult to communicate the details of the problem and solution domains across different disciplinary 'languages' (Bucciarelli 2002). Members' ability to discern incompatible design decisions is thus often poor, engendering excessive iteration (Urup 2016).

Several methodologies based on mental models have been used to study the above problems; e.g., (Casakin and Badke-Schaub 2017). However, these inquiries are mostly descriptive, focused on quantifying the overall dynamics of collaboration. But the purpose of Design Research is not simply to comprehend design, but to exploit that comprehension in order to take action, to wage war against that which defiles design, yielding an ever more effective practice with which to enrich the world. As the majority of the existing literature on this topic does not offer concepts of robust tools for rectifying what they highlighted as lacking, the aim of this work is to propose such a tool.

Like Buchanan (1985) and several others, Halstrøm (2017) argues for the significance of persuasion in the design process, contending for an explicitly rhetorical view of it. Even though existing models of the process of design may be accurate, "they provide little advice on how to deliberate and make judgments in terms of intention and argumentation for designers" (Halstrøm 2017). Using classical rhetorical concepts, Halstrøm crafted a holistic model to help designers clarify their intentions and persuasively argue their way through design tasks. Due to the simplicity and seeming efficacy of this model, it was taken as the starting point from which a design game for alleviating the foregoing issue was moulded out.

In other words, this work is about designing an intervention for the problems caused by the failure to align expectations regarding the project between all the stakeholders. It should be noted that despite codesign often continuing throughout a Design-Build project, this work focused on intervening in its early stages, though the result is highly adaptable to the latter phases too.

This research was divided into four stages: literature review, problem space exploration (i.e. research methods), solution development (i.e. design process), and discussion. The literature review describes the foundations of the three domains of knowledge (mental models, rhetoric, and design games) that were most salient in understanding the design space under consideration. In the following section are laid out the methods of analysis that were applied to chart out the problem space, using as inspiration the theories discussed above. In the next section the process of designing a solution for the problem is detailed; for this the theory of design games and boundary objects provided a solid basis. The paper then concludes with a discussion of the efficacy of this solution, and the way forward.

\section{LITERATURE REVIEW}

Since the issue of shared understanding is at root a problem of aligning mental models, a summary of that topic will be presented. This is followed by an overview of the art and methodologies of rhetoric, which is our chosen methodology for tackling the issue. The last subsection here is about boundary objects as our starting point for exploring the practical subspace of the solution space. 


\subsection{Mental models}

The concept of a mental model is a powerful method in studying mental processes in design. These are simplified representations of the world that prevent the mind's being overloaded with data; more or less subconsciously constructed frameworks that allow quick gleaning and processing of new information (Smyth and Morris 1994, Badke-Schaub, Neumann et al., 2011). Alignment between individual mental models arises from communication, resulting in a 'shared mental model'. Such alignment has been shown to enhance the team's coordination and performance (DeChurch and Mesmer-Magnus 2010).

Casakin and Badke-Schaub (2017) studied shared mental model formation in a team of architects and clients, presenting a simple and solid methodology for mental model sharedness quantification. Namely, the design sessions were recorded and coded into the three different types into which shared mental models have usually been categorized into (Edmondson and Nembhard 2009): Task (problem and solution space), Team (individual as well as multiple designers), and Process (the dynamics of designing). Thus, the frequencies and interplay between these in the recorded session could be analyzed. It was found that sharedness is achieved most effectively by emphasizing discussion belonging to the Task model (especially idea generation and solution analysis), which tends to be the most common type of interaction, followed by that belonging to the Team model (Badke-Schaub, Neumann et al., 2011).

\subsection{Rhetoric}

According to Aristotle, Rhetoric is "the faculty of observing in any given case the available means of persuasion" (Rapp 2016). Every persuasive utterance or piece of writing, whether political manipulation of crowds, or a kid pleading with her parents to visit Disneyland, is a rhetorical act. In Aristotle's fundamental treatise of the subject, he deemed it a counterpoint and an analogy to dialectic (Rapp 2016): "what dialectic is for the private or academic practice of attacking and maintaining arguments, rhetoric is for the public practice of defending oneself". As such, since communication in teams can be considered a complex interplay, via persuasive language, between embodied minds holding differing mental models, with the aim of crafting a shared one, rhetoric seems an apt conceptual pond from which to fish out insights, or even a whole framework, for the problems plaguing communication in co-design practice.

One of the core aspects of rhetoric is the topos, a general argumentative form or scheme, based on which specific arguments can be derived. In line with the word's original meaning of 'place', the topoi can also be thought of as different viewpoints from which to survey an issue, or from which to find weak flanks to launch offensives at. For example, (Giacomin 2014) argued that human centered design is organized around answering the rhetorical questions of increasing layers of complexity.

After a two-millennia-long lapse, the field was resuscitated in the 1960s as New Rhetoric, with a shifted aim and amplified canon (Enos and Brown 1994). In contrast to the old focus on molding formal and aesthetic features of oral or written text, in order to manipulate an audience to conviction, the modern theories are about discourse as action (Enos et al., 1996): how writing or speech can be used to enlighten, persuade, amuse and inspire people, regardless of the form and scope of discourse. The contemporary theorists McKeon and Backman (1987) have explored the potential of rhetoric as a system of guidance for innovation; they argue for generalizing the art from mere dialectics and oration to uncovering and creating value : "We need a new art of invention and discovery in which places [i.e topoi] are used as means by which to light up modes and meanings of works of art and natural occurrences and to open up aspects and connections in existence and possibility."

Halstrøm (2017) has taken this idea of rhetoric as an art of invention and created a practical framework whereby to apply it to design. Despite the thoroughness of Aristotle's and Cicero's lists of topoi, Halstrøm found their expansiveness to render them too unwieldy for use in design. He thus adopts Hermogenes' two sets of six topoi, which the venerable thinker curated so as to maximize their potential for amplification of persuasion. At least one topos is taken from each set, combined, and thrown into a designer's right-side brain to yield a variety of arguments:

- Circumstance topoi: time (khronos), place (topos), person (prosôpon), way (tropos), act (prâgma), cause (aition).

- Parallel topoi: comparison (parabolê), example (paradeigma), minor (mikroteron), greater (meizôn), equal (isos), opposite (enantion).

In short, the framework is as follows. Firstly, the designers frame some 'values to be celebrated' by the artefact. These are then 'amplified' using the above topoi, coming up with means for implementing the values in practice. Lastly, the designers deliberate about the ideas, envisioning whether they would be interpreted by the artefact's audience (i.e. users) in an optimal way. 


\subsection{Design games and boundary objects}

The solution of this paper took the form of a design game; the power of design games for mental model alignment potential is notable, their being excellent "in creating a play spirit where a shared language is actively being constructed through design game materials" (Vaajakallio 2012). These materials are a subset of the concept of 'boundary objects', "those objects that both inhabit several communities of practice and satisfy the informational requirements of each of them. Boundary objects are thus both plastic enough to adapt to local needs and constraints of the several parties employing them, yet robust enough to maintain a common identity across sites" (Bowker and Star 2000). In other words, they are media that enable translation of information across the vast gulfs between divergent mental models, e.g. between different professional domains (Bucciarelli 2002). Furthermore, it is beneficial for boundary objects to be physical rather than digital: physicality boosts thinking and widens one's creative capacity, for it enables the body to act as a cognitive extension of the brain, as encapsulated in Tversky's embodied cognition (Tversky and Hard 2009) and Watsuji's embodied intersubjectivity (Krueger 2013). Hence, the materials of a design game should be designed as 'things-to-think-with' (Vaajakallio 2012 ). In the case of this project, this concept was integrated with those of rhetorical optimization (via Halstrøm's framework) and insights about the formation of shared mental models, yielding a medium to act as lubricant for embodied co-creation.

\section{RESEARCH METHODS}

The first subsection below is a description of the workshops from which our data was gathered. The following subsection gives an overview of how topoi (see Section 2.2) relevant to the foregoing design space (i.e. of the intervention for Design-Build workshops) were extracted, and the last subsection exhibits the topoi. From these, the solution was then developed in Section 4.

\subsection{Cases}

The kernel of data from which our analysis of the design space began was acquired by recording audio from two Integrated Design-Build Big Room design workshops:

- Hospital: Two half-hour sessions of refining spatial functions with representatives of the future building's users (mainly nurses and doctors), around draft plans of relevant wards. Three architects each embedded him/herself into a group of two to six people. The first session was with representatives from the maternity/children's ward, the second with those of the psychiatric ward.

- School: Two different, simultaneous meetings, lasting half an hour. The topic of one meeting was the refinement of the spatial configuration and functions. That of the other was the building's location on the lot. The groups, of five people each, were composed of architects, design managers, engineers, users, and a client (from the city council).

\subsection{Topos extraction}

The authors used Atlas.ti (2018) to transcribe the recordings, yielding a set of topoi. The process with more or less overlapping steps was as follows:

1. Delineating the transcription into units, each dealing with (roughly) one theme.

2. Repeatedly reading through the transcriptions, extracting recurring topoi.

3. Curating these topos candidates. However, this step was not truly separate from the transcription and the above step.

The curation procedure is outlined in Figure 1. It is a series of requirements that each topos candidate has to fulfill. They are formulated so as to ensure that the topoi are maximally relevant to any Integrated Design-Build project and, considering the diverse target users of my intervention, universally understandable.

Looking beyond this process to the designing of the solution in Section 4, the requirement of general understanding inherent in the fourth step in Figure 1 (Not too technical; explorable by anyone) is the foremost element up to now that contributes towards mental model alignment: it diminishes the need for group members who lack technical expertise to form futile mental models of things that they will not be able to properly explore, while forcing the group's technical experts to simplify their language to the lowest common denominator. In other words, that step is for reducing the issue that "The indeterminacy of translations across object worlds is rather severe; one participant's rabbit parts may be another's cantilever beam" (Bucciarelli 2002). 


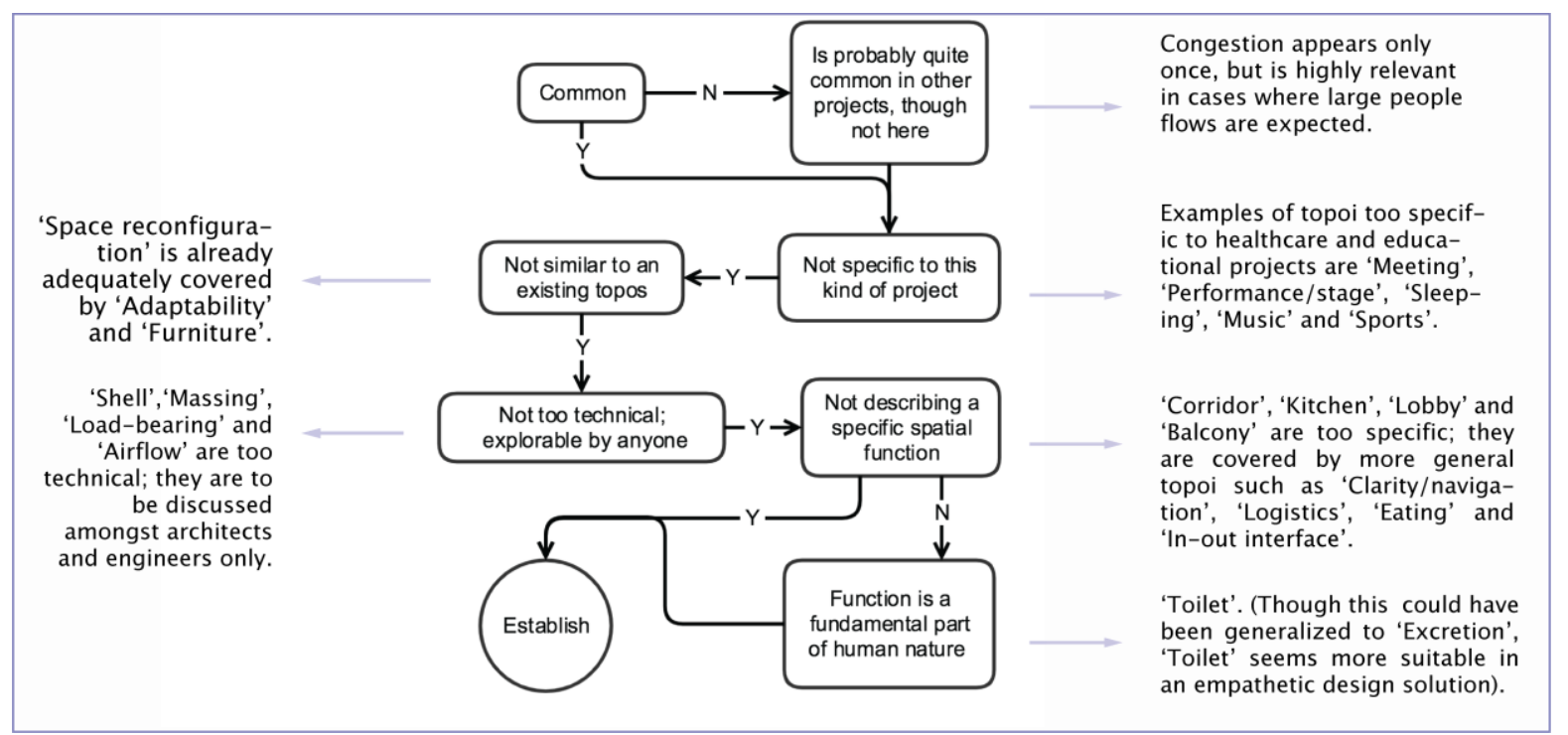

Figure 1. The topos curation process (starting from the requirement for commonness).

\subsection{Resulting set of topoi}

The set of topoi that the above extraction process yielded is shown in Table 1. Note that Time, Cause and Act are from Hermogenes' six circumstance topoi. The other three, namely Place, Way and Person, were omitted due to their overt ubiquity in an architectural context rendering them rather futile; after all, "architecture is the art and science of making sure that our cities and buildings [place] actually fit with the way we [persons] want to live our lives" (Basulto 2014). However, this was a subjective decision, and it remains to be seen or argued whether explicit consideration of those three would in fact be valuable in an intervention such as was created here.

Table 1. The set of 30 general architectural topoi.

\begin{tabular}{|c|c|c|c|}
\hline Privacy & Visual connection & Clarity/navigation & Peace/turmoil \\
\hline Storage & Sharing & Nature & Logistics \\
\hline Hygge & Future & Extendability & Folly \\
\hline Time & Cause & Play & Day/night \\
\hline Act/process & Dense/sparse & Adaptability & Central/peripheral \\
\hline Distance & Eating & Congestion & Separate/unified \\
\hline User state & Toilet & In/out interface & Rest \\
\hline Noise & Collaboration & & \\
\hline
\end{tabular}

Having coded the units, ATLAS.ti (2018) was used to find the topoi's co-occurrences, i.e. how many times they occurred with each other in the same unit. Here the topoi that occur with each other were called affiliates (Figure 2). As an example, a topos with a relatively high amount of co-occurrences (23) was Play, resulting from the nature of the two cases: there was much discussion of recreational activities for the school, and one of the hospital sessions was about the children's ward. The most common affiliates of Play (3 co-occurrences each) were Rest, Sharing and Separate/unified. 


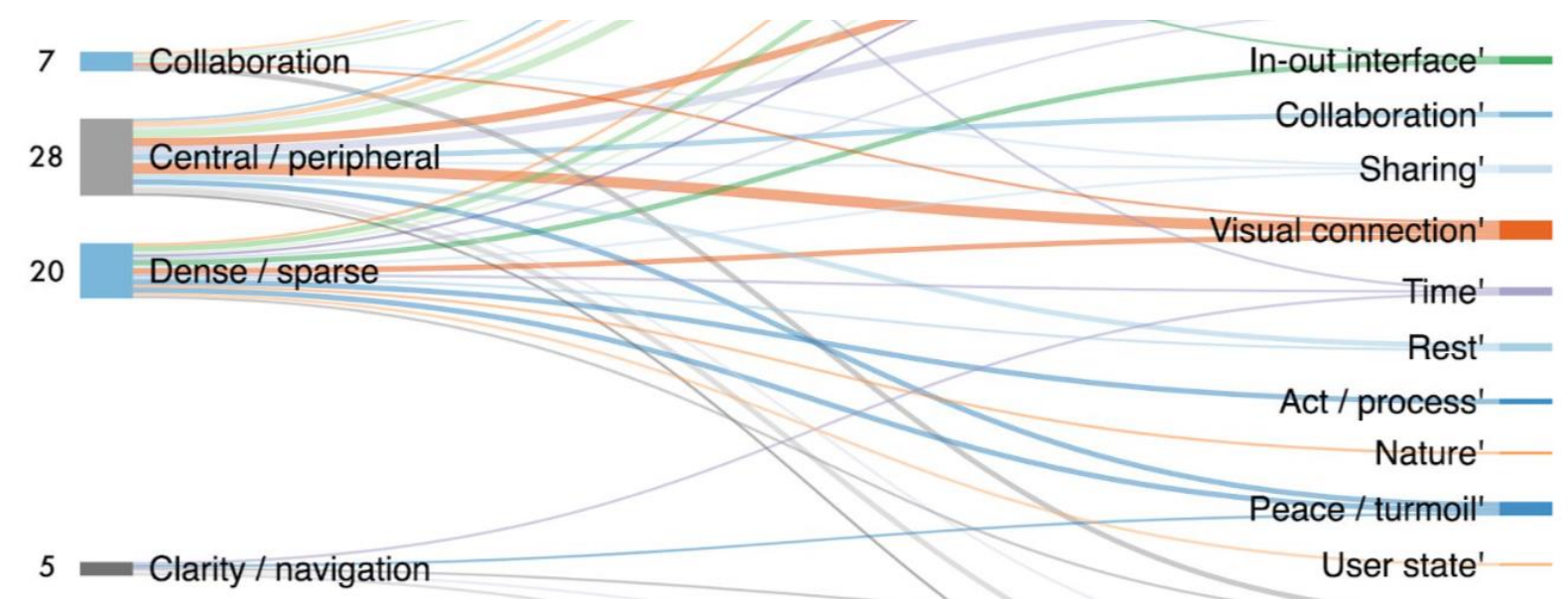

Figure 2. Examples of the affiliates of four topoi (on the left). The numbers are the total cooccurrences, e.g. 'Collaboration' occurred 7 times with other topoi.

\section{DESIGN PROCESS}

In the first subsection below, the iterative process, describing briefly each version, is summarized. The second subsection contains a description of the testing that the iteration was interspersed with, in addition to a summary of the final evaluation of the solution. In the last subsection, a summary of the solution's mechanics is presented.

\subsection{Outline of iterations}

Being about introducing an intervention, this project takes the form of research through action. The solution's design process was therefore structured according to the classical action-research approach (Carr and Kemmis 1986): 'plan-act-observe-reflect'. More specifically, the alternating designing and testing phases comprised 'reflection + planning', and 'acting + observing' respectively.

The first design decision was for the solution to be a design game, since design games manifest a host of values highly relevant to the aims of this project (Vaajakallio 2012): intuitiveness, an engaging quality, idea generation, and the lowering of the mental threshold for sharing. In addition, familiarity with the benefits of physical boundary objects (as explained in the Literature Review) led to the eschewing of any notion of a digital solution in favor of tangibility. More specifically, the game should be card-based: a deck of cards is an excellent medium for distributing multifaceted data in a standardized format to many people, and is hence naturally suited for embodying topoi.

Next, since the analytic process outlined in the above section had been created with inspiration from Halstrøm's rhetorical framework, and the cornerstone of this solution was thus already composed of the concept of the topoi therein, it was decided to implement the framework as the format of the game mechanics, too. First the players would choose values to celebrate in their project; next they would amplify the values by coming up with ideas inspired by the topoi; lastly they would envision the impact of those ideas on the project's users and on themselves. This concept was thus laid as a foundation on which to develop the game. The iteration to the final version of the game through three intermediate versions, as well as the associated tests, is summarized in Table 2. 
Table 2. The iteration to the final version of the game through three intermediate versions, as well as the associated tests. The physical game materials are shown in bold.

\begin{tabular}{|c|c|c|}
\hline & Mechanics \& boundary objects & Improvement needs from testing \\
\hline 1 & $\begin{array}{l}\text { A design game based on hexagonal cards, one topos on } \\
\text { each (i.e. topos cards). Players would first come up with } \\
\text { the values of the project and write them on empty } \\
\text { hexagonal cards, then place one of them in turn on a } \\
\text { playing field. Next they would get inspired by various } \\
\text { topos cards, charting out some design space with each } \\
\text { one. The aim was to bridge the value card with 'goals' a } \\
\text { few hexagons away using the topos cards. }\end{array}$ & $\begin{array}{l}\text { - Hard to come up with high-quality } \\
\text { values on the spot. } \\
\text { - Players forgot that their ideas } \\
\text { should amplify the value. } \\
\text { - They found the spatial rules of } \\
\text { where a card can be placed too } \\
\text { restrictive of their creativities. } \\
\text { - They wished for time to brainstorm } \\
\text { individually too. }\end{array}$ \\
\hline 2 & $\begin{array}{l}\text { Metaphor cards to induce creativity in the value } \\
\text { brainstorming phase. Eschewing of the hexagonal cards and } \\
\text { the spatial rules, and transforming the topos cards into the } \\
\text { form of fans, each plane of the paper manifold containing } \\
\text { one affiliate of the topos in question. The players again get } \\
\text { inspired by any of these cards, this time individually, and } \\
\text { write the resulting ideas onto empty cards, adding them to } \\
\text { a cluster around the value card. They explain the concepts } \\
\text { to each other, and create a little story from each cluster. }\end{array}$ & $\begin{array}{l}\text { - The players did not add ideas } \\
\text { enough to each other's clusters. } \\
\text { - Again, they forgot that their ideas } \\
\text { should amplify the value (though not } \\
\text { as much as before). } \\
\text { - It was difficult for them to come up } \\
\text { with stories of even mediocre } \\
\text { quality, and to collaborate in } \\
\text { creating them. }\end{array}$ \\
\hline 3 & $\begin{array}{l}\text { Adding a third dimension to boost the game's physicality } \\
\text { and play spirit: the addition of ideas is now represented by } \\
\text { the physical metaphor of making flowers bloom, by the } \\
\text { idea cards being in the form of petals, added onto stalks } \\
\text { (rubber-coated wire) that are pushed into holes on a } \\
\text { (wooden) base on which lays the value card. The forming } \\
\text { of shared mental models about the values was improved by } \\
\text { making the players create clusters of ideas and framing } \\
\text { them together into one phrase. And the players' passivity } \\
\text { was tackled by changing from individual to pairwise } \\
\text { ideation during the amplification phase, and to pairwise } \\
\text { storytelling, inducing dynamic and intimate collaboration. }\end{array}$ & $\begin{array}{l}\text { - Framing the integrated values as } \\
\text { questions to enhance their dynamic } \\
\text { quality. } \\
\text { - Ending the deliberation phase with } \\
\text { an evaluation step, as in Integrated } \\
\text { Design-Build projects, a shared } \\
\text { understanding of possibilities and } \\
\text { requirements is not enough; a mental } \\
\text { model of the realizability of the } \\
\text { concepts is critical too. }\end{array}$ \\
\hline 4 & $\begin{array}{l}\text { Addition of an evaluation step with an evaluation card to } \\
\text { the end of the deliberation phase, where the three most } \\
\text { important idea clusters (blooms) are chosen, and their } \\
\text { relative economic weights decided collectively. }\end{array}$ & \\
\hline
\end{tabular}

\subsection{Testing}

Each test was conducted with a carefully selected group of three or four people; first design researchers, then design and management students, and lastly with an architect and construction engineers and managers (who were employed at a construction company). In other words, except for the final test, due to practical limitations the bunch of stakeholders in each test was very homogenous, providing a suboptimal approximation of the intended audience space. The sampling was purposive, as it was based on "the researcher's judgement as to typicality or interest" (Robson 1993). Though this method was far from perfect, in Robson's words "[t]he exigencies of carrying out real world studies can mean that the requirements for representative sampling are very difficult, if not impossible, to fulfill."

The improvements that were integrated into each iteration of the game, detailed in Table 2, came from both the test participants' feedback and the authors' observations of their performance and results. Furthermore, during the final test (Figure 3 left), a rudimentary quantification of the increase in mental model alignment was performed by comparing the participants' concept maps. This technique (also called Constructed Shared Mental Models) has previously been used in the context of design by Badke-Schaub, Neumann et al. (2007). The players simply sketched out a map of concepts 
that relate to their vision of the design task, as many as they could within five minutes. By doing this both before and after playing the game, it was found out that the sharedness of ideas increased from 6 to 15. The game thus clearly has potential in achieving its objective, though obviously far more testing is needed to confirm this.
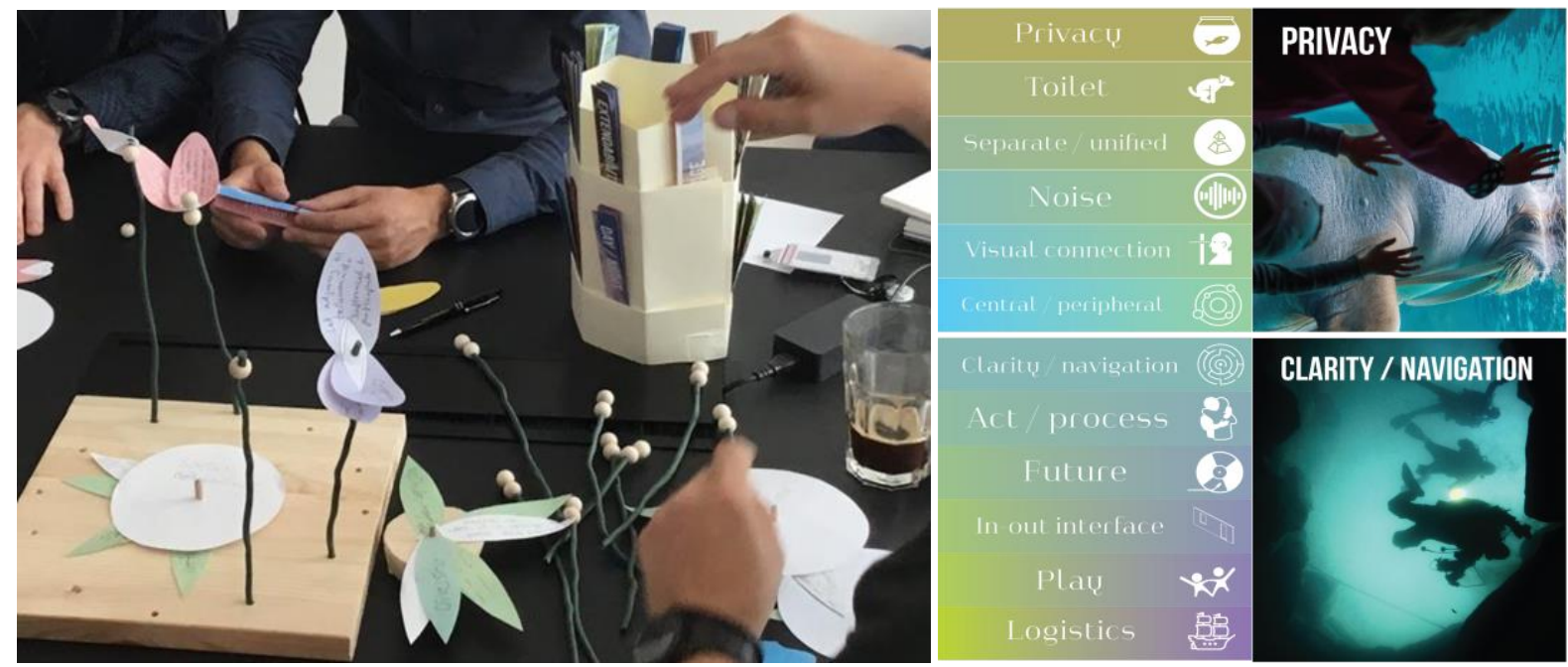

Figure 3. Left: Players conducting the pairwise ideation during the final test. Idea clusters stuck into an amplification base are visible on the left, with the value 'Sociality / knowledge sharing' under amplification. On the right can be seen the folded form of the topos cards. Right: Examples of the topos cards (yet to be folded).

\subsection{Final version}

A summary of the game's mechanics is shown in Figure 4. It begins with individual ideation of the project's values using metaphor cards for inspiration; the value proposals are then communally clustered, and the clusters named. Next, one value is chosen in turn and amplified in pairs by coming up with concepts (in the problem, solution or audience spaces (Halstrøm 2017)) that would manifest it, using topoi cards for inspiration (Figure 3 right). These concepts are then described to another pair, which fashions from some of them a brief story about an envisioned user of the project's result. Finally, the three most important clusters of concepts are chosen, and their financial feasibility estimated, before moving onto amplifying the next value.

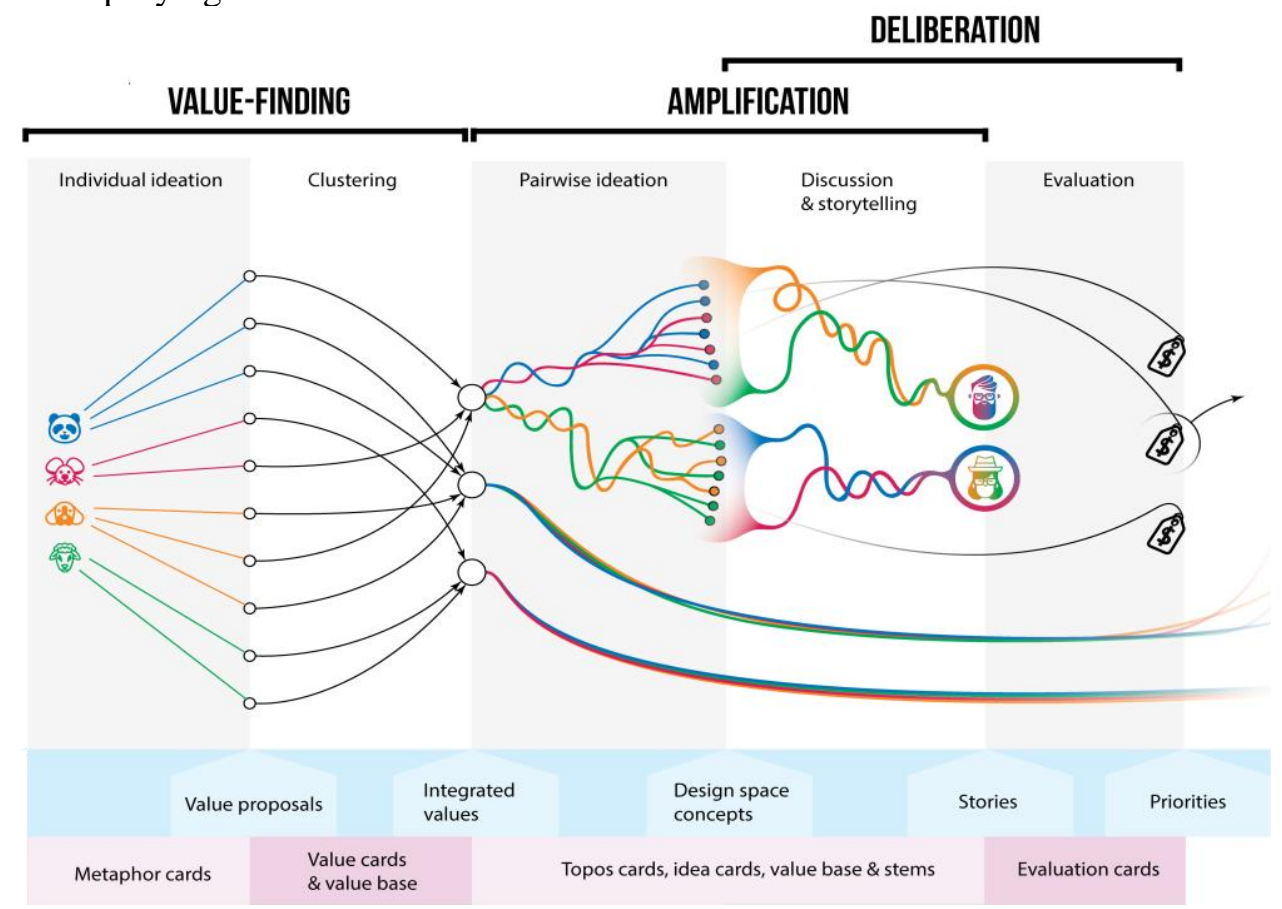

Figure 4. The game's mechanics. The blue bar underneath shows the output of each step, while the pink bar shows the materials of each step. 


\section{DISCUSSION: WAY FORWARD}

Being exploratory in nature, this work was intended simply as a preliminary probe into the design space of the foregoing Integrated Design-Build problem, without emphasizing reliability. This is discernible in various aspects of the analytic process: small dataset; only audio data; subjective topos curation; subjective coding. These weaknesses are the primary ones to tackle if the methodology presented above is to be enhanced into a robust tool.

Given a repository of many Integrated Design-Build session recordings, automation would obviously be superior to manual topos curation. The most promising way to apply automation here would be via topic models, which are statistical models used in text analysis to discover latent topics, using word co-occurrence. In fact, this project's recordings were fed to a topic modeling algorithm (Chuang, Manning et al., 2012), but the results were incoherent due to dataset's smallness. Indeed, hundreds of sessions would have to be recorded for this direction to prove useful.

As for refining the theoretical basis of the solution, there are several layers that could be added into the mix. For example, the notion of the three forms of persuasion in rhetoric (ethos, pathos and logos), and the idea of the parallel topoi in Halstrøm's model (see the Literature Review). Though some parallel topoi did in fact sneak into the set of 30 topoi (Dense/sparse, Separate/unified, and Central/peripheral), there may well be potential in explicitly integrating parallel topoi, which could be used to force the players to mine even deeper into the conceptual veins of circumstance topoi.

There is moreover an important aspect of shared understanding that was omitted in this project, namely the concept of the three mental models of collaboration (Edmondson and Nembhard 2009): Task, Process and Team. Not only could transcripts be coded with these as an additional layer, but any utterance could be further categorized according to Badke-Schaub's methodology (e.g. 'Solution analysis', 'Solution evaluation', and 'Explanation' are some of the Task model's subtypes). The data this would yield may then be used to gain insights into ways of optimizing the solution, or even into new forms of rhetorical design games.

Finally, it ought to be noted that the communication used in the two cases consisted of a rich mixture throughout the language-object continuum (Fleming 1998). Though this can be taken as a sign of a robust design mindset pervading the team, it was problematic for this research due to the large amount of indexing: pointing at the floor plans that lay on tables or hung from walls, enabling the members to easily refer to any space in the envisioned sociotechnical systems. "The language of design is often highly indexical, so intimately connected to the context of its production that it can be removed from that context only by rendering it meaningless" (Fleming 1998). Indeed, without afterwards having the boundary objects to mediate meaning, a significant amount of the recordings was impossible to understand. To rectify this in future works, the first step would obviously be to record video, which could then be arduously analyzed to extract the meaning of the indexical language peppered throughout (as shown superficially in Fleming 1998, p. 48). However, for high amounts of data, an artificial intelligence (AI) capable of analyzing physical language would have to be applied. Towards this end, the perspectives offered by the embodied cognition of (Tversky \& Hard 2009) and by Watsuji's embodied intersubjectivity (Krueger, 2013) seem promising springboards.

\section{CONCLUSION}

This project was about designing an intervention for the problems caused by the failure to align expectations regarding the project between all the stakeholders. The final test gave some evidence that the game indeed is successful, with the alignment of the individual mental models more than doubling. However, far more tests would have to be conducted in order to ascertain the validity of these initial results. In any case, the intervention clearly has potential to be developed into a tool that could indeed to a large extent alleviate the issues in Integrated Design-Build originating from poorly shared understanding. The participants of the final test were of a positive opinion about the solution's power, recommending its further enhancement for use in construction companies, and perhaps for training in construction managements academies. Moreover, not only could the game prove valuable in practice, but the highly flexible methodology used here has great potential for integration of further aspects of rhetoric, as well as for creating interventions for related domains, such as service design. 


\section{REFERENCES}

Apelgren, S., et al. (2005), “Snubesten i byggeriet. Rapport, Byg, DTU”, Vol. R-107, Department of Civil Engineering, DTU, Copenhagen, Denmark.

Atlas.ti (2018), “AtlasTI: The Qualitative Data Analysis \& Research Software”, Available at: atlasti.com.

Badke-Schaub, P., et al. (2011), "An observation-based method for measuring the sharedness of mental models in teams", Coordination in human and primate groups, Springer: pp. 177-197.

Badke-Schaub, P., et al. (2007), "Mental models in design teams: a valid approach to performance in design collaboration?", CoDesign Vol. 3 No. 1, pp. 5-20.

Basulto, D. (2014), “AD Interviews: Bjarke Ingels / BIG”, Nov. 2018.

Bowker, G. C. and Star, S. L. (2000), Sorting things out: Classification and its consequences, MIT press.

Bucciarelli, L. L. (2002), "Between thought and object in engineering design.” Design Studies, Vol. 23 No. 3 , pp. 219-231.

Buchanan, R. (1985), "Declaration by design: Rhetoric, argument, and demonstration in design practice”, Design Issues, pp. 4-22.

Carr, W. and Kemmis, S. (1986), Becoming critical Lewes, Falmer Press). CROSS, K.P. (1987) Teaching for Learning, Bulletin of the American Association for Higher Education Vol. 39, pp. 3-7.

Casakin, H. and Badke-Schaub, P. (2017), "Sharedness of team mental models in the course of design-related interaction between architects and clients", Design Science Vol. 3.

Chuang, J., et al. (2012), “Termite: Visualization techniques for assessing textual topic models”, Proceedings of the international working conference on advanced visual interfaces, ACM.

DeChurch, L. A. and Mesmer-Magnus, J. R. (2010), "The cognitive underpinnings of effective teamwork: A meta-analysis", Journal of applied psychology Vol. 95 No. 1, p. 32.

Eckblad, S., et al. (2007), "Integrated project delivery-a working definition”, AIA California Council, Sacramento, CA Vol. 25.

Edmondson, A. C. and Nembhard, I. M. (2009), "Product development and learning in project teams: The challenges are the benefits", Journal of Product Innovation Management, Vol. 26 No. 2, pp. 123-138.

Enos, T., Enos, T. J., and Publishing, G. (1996), Encyclopedia of Rhetoric and Composition: Communication from Ancient Times to the Information Age, Garland Pub.

Fleming, D. (1998), "Design talk: Constructing the object in studio conversations", Design issues Vol. 14. No. 2, pp. $41-62$.

Giacomin, J. (2014), “What is human centred design?” The Design Journal Vol. 17 No. 4, pp. 606-623.

Halstrøm, P. L. (2017), "Rhetorical Design Studies: The Art of Making Design Choices Explicit. Design and Conservation. Copenhagen, Denmark", The Royal Danish Academy of Fine Arts. Doctoral Dissertation, p. 130.

Henisz, W. J., et al. (2012), "Toward a unified theory of project governance: economic, sociological and psychological supports for relational contracting." Engineering Project Organization Journal, Vol. 2 No. 1-2, pp. 37-55.

Krueger, J. (2013), "Watsuji's phenomenology of embodiment and social space”, Philosophy East and West, pp. 127-152.

McKeon, R. P. and Backman, M. (1987), Rhetoric: Essays in Invention and Discovery, Ox Bow Press.

Rapp, C. (2016), “Aristotle's Rhetoric”. The Stanford Encyclopedia of Philosophy, E. N. Zalta, Metaphysics Research Lab, Stanford University, Stanford, USA.

Robson, C. (1993), Real world research: A resource for social scientists and practitioners-researchers, Blackwell Pushers, Massachusetts.

Siebken Schultz, C. (2012), Byggeriets produktion af svigt i et strukturationssperspektivet studie af reaktive og proaktive problemlosningspraksisser, Chalmers University of Technology.

Smyth, M. M. and Morris, P. E. (1994), Cognition in action, Psychology Press.

Thuesen, C. (2007), “Anvendelse af den rette viden - et studie af byggeriets kulturelle organisering”. Doctoral Dissertation, Department of Civil Engineering, Technical University of Denmark, p. 271.

Tversky, B. and Hard, B. M. (2009), "Embodied and disembodied cognition: Spatial perspective-taking", Cognition, Vol. 110 No. 1, pp. 124-129.

Urup, L. (2016), “Integrated Design-Build Management - Studying Institutional Processes to Understand Project Coordination \& Performance. Chalmers, Civil and Environmental Engineering, Construction Management", 2016, Chalmers University of Technology, Gothenburg, Sweden, Doctoral Dissertation, p. 181.

Vaajakallio, K. (2012), "Design games as a tool, a mindset and a structure. School of Arts, Design and Architecture". Helsinki, Finland, Aalto University, Doctoral Dissertation, p. 243.

\section{ACKNOWLEDGMENTS}

We are grateful for Josef Oehmen's, Philip Cash's, and Lauri Koskela's feedback during this project. 